IP Periodica Polytechnica

Transportation Engineering

43(4), pp. 189-198, 2015

DOI: $10.3311 /$ PPtr.7742

Creative Commons Attribution (i)

RESEARCH ARTICLE

\section{Risk Factors Contributing to Taxi Involved Crashes: A Case Study in Xi'an, China}

\author{
Yangdong Zhao ${ }^{1,2^{*}}$, Jun Zhang ${ }^{1}$, Xin $\mathrm{He}^{2}$
}

Received 03 October 2014; accepted after revision 12 December 2015

\begin{abstract}
Using the 612 valid samples deriving from the original 6259 crash reports in Xi'an from 2006 to 2011, comparative statistics and systematic analysis are employed to describe the features of taxi crashes. It is found that the middle-aged male drivers with lower education background are much more likely to be involved in a crash and it indicates that 438 cases or approximate $72 \%$ of all crashes are related to those aged 26 40 years, and the taxi drivers with 3 5 years experience are at greater risk for crashes than other groups. Additionally, the statistics also presents that a big proportion among occurred with the most frequent type of sideswipe collisions (44.77\%), on major segments or intersections, in two most dangerous periods (8:00 10:00 \& 16:00 18:00), at weekends, and during November, December and January, but night records more fatal and serious crashes due to fatigue and poor lighting. Similarly with the motor vehicle accidents, nearly $89 \%$ are associated with drivers' over speeding, unbelted and other types of improper or illegal behaviors. Meanwhile, the average 9.72 working hours also performs significant contribution to the frequency of crashes.
\end{abstract}

\section{Keywords}

taxi crash, contributory factor, risk behavior, sideswipe collision, safety performance

\footnotetext{
${ }^{1}$ School of Highway, Chang'an University, Xi'an, China

${ }^{2}$ CCCC First Highway Consultants Co. LTD, Xi' an, China

*Corresponding author, e-mail: hityangdong@163.com
}

\section{Introduction}

Over the past three decades, the rapid expansion of China's economy has lead to dramatically increasing urbanization and motorization and an alarm growth in road traffic injuries and fatal fatalities (Wang et al., 2011). Particularly, a number of motor vehicles in China has increased from 108 million units in 2004 to 207 million units in 2010, an average rate of $11.49 \%$ per year. In 2010, however, 219,512 crashes occurred with 254,075 injuries and 65,225 fatalities, $40.37 \%$ lower than the peak year of 2002, due to a series of national safety improvement programs. Theoretically, professional taxi or bus or lorry drivers are at a greater risk of being involved in a vehicle crash, due to their occupational exposure to hazardous fatigue and stress (Lam, 2004; Mitsakis, 2015). With the huge amount of this professional group all over the world, it causes a wide concerned occupational health issue.

Many studies have been conducted to examine the physical or behavioral characteristics of taxi drivers involved in crashes and determine the contributory factors. As early as in 1997, Maag et al found that age had significant influence on the number and the severity of crashes and the taxi drivers aged less than 30 years were much easier to be involved and injured in crashes than the older group (Maag et al., 1997). In many studies, taxi crashes are found to be associated with the driver's age, type of license, employment status (full or part- time), satisfaction of pay, seat-belt usage, and other factors (La et al., 2013). In Spain, female or non-helmet use drivers had a high crash frequency of lower severity, but the increased age can cause severe injuries or death considerably in crashes at higher risk, which should be taken into account while assessing the effects of individual factors on the risk of death after a crash (Newman et al., 2014; Sokolovskij and Prentkovskis, 2013).

Given the significant effect of exposure to hazardous environments on the health of taxi drivers, some researchers have emphasized their importance on the occupationally related risk factors contributing to the occurrence of crashes, including fatigue (Christoforou et al., 2012), sleepiness (Firestone, Mihaere, Gander, 2009), vision damage (Maag et al., 1997), mental stress (Mann et al., 2010), duration of working hours 
(Hitosugi, 2012), etc. While examining the associations between individual factors and the crash risk of taxi drivers through 7923 samples in New South Wales (NSW), Australia over the time of 1996 2000, it was found that females confronted significantly higher risk of injuries and fatalities in crashes, compared with their male counterparts, and it was even more serious for those who work in night or do not carry passengers (Lam, 2004). Additionally, busy or workload taxi drivers were more likely to be involved in a crash due to mental stress and work-related fatigue and than those with more break time during the working day (Tseng, 2013).

Behavior of taxi drivers may also play an important role for the involvement in a crash. In Nanjing, China and Israel, the taxis drivers are less likely to use seat belt than other groups (Wang et al., 2014). During the period of 2008 Beijing Olympic Games, over 174 Beijing taxis out of the surveyed 231 samples did not use the seat belt (Fleiter, 2009). Efforts, however, have still not been made to explore the factors influencing the use or misuse of seat belts in China. The findings from 248 taxi and bus drivers in Wuhan, China highlighted that risky driving behaviors was significantly affected by their attitudes toward traffic rule and speed choice (La et al., 2013; Rao and Rao, 2015). Since health and safety training plays a key role among taxi drivers, it is necessary to impose strict laws and initiate rigorous enforcement programs for reducing and preventing the improper / illegal driving behaviors of taxi (Chin and Huang 2009).

Xi'an, the capital of Shaanxi Province is an important cultural, industrial and educational center with over 3,100 years of history in northwest China and is significantly motorized. Due to rapid economic development and urbanization, the number of four-wheeled motor vehicles dramatically increased from 143,799 in 2001 to $1,153,521$ in 2011 in Xi'an city. During this period, the taxi industry proves a great success with the superior quality of service and grew successfully to a profitable business, which, as a result, increased the number of licensed taxi vehicles. Today, there are at least 22 taxi companies providing service in $\mathrm{Xi}$ 'an today, with sizes ranging from less than 100 taxis to over 1,100 , plus a number of unlicensed vehicles. In the past year of 2011, an average approximate 500 crashes occurred per day and taxis are completely or partially responsible for a large proportion of these records. However, less attention has been focused on the safety related issues of the taxi during the previous decade.

Accordingly, the primary purpose of this study aims at analyzing the crash characteristics associated with taxi services in Xi'an, in order to identify the major contributory factors to such problems. To achieve this objective, 612 taxi-related accident samples are selected from the originally reported 6259 cases in Xi'an city from 2006 to 2011, and a limited questionnaire survey of taxi drivers and firms is conducted for understanding the operating features of taxi service. After describing the data collection procedure, this paper presents a detailed analysis of taxi-related crashes in Xi'an, including the gender, age, marital status, education background, license status, driving experience of the drivers involved, temporal / spatial distribution of crashes and potential causes. At the end of the paper, a brief discussion of major findings is given and the paper concludes by proposing several recommendations.

\section{Data Assembly}

The original crash data in Xi' an over the period of 2006 2011 is obtained from the Traffic Accident Database System that is released by the Ministry of Public Security of the People's Republic of China and maintained by the local Police Force and Transport Department. This system provides precise crash messages manually in three profiles: crash environment, casualty injury, and vehicle involvement.

The crash environment profile gives the date, time and location of crash occurrence, weather conditions, traffic flow states, roadway geometrics, the percentage of heavy trucks, and status of traffic facilities, etc. The casualty injury profile provides the demographic description of injuries, mortalities, and associated severity that is divided into three levels: fatal, serious, and slight, the role of victim, the use of a seat belt, the location of involved bicyclists, motorists, passengers and/or pedestrians, etc. The vehicle involvement profile illustrates the driver messages, including gender, age, driving experience, license status, the possible influence of fatigue, alcohol / drug impaired, illness, and / or asleep, etc., and crash information for each involved vehicle (size, collision position, velocity of before and after collision, skidding and / or rolling marks trajectory, braking performance, etc.).

Moreover, the policy record also gives a detailed crashes story about the interpreted comments from the attending police officers, photographs, statements of vehicle examiners, interviews and witnesses, which supplement rich information in reconstructing the entire crash process and identifying the potential factors that have contributed to the occurrence of crashes.

A sample of 6259 original crash cases during the recent six - year period of 2006 to 2011 inclusive is selected from the official database through Xi'an Traffic Policy Department. Unfortunately, some necessary information is sometimes missed or incomplete in the crash records (e.g., the condition of the road surface, control pattern of the intersection, etc.). Thus, 273 records accounting for $4.36 \%$ of the original collection are removed from the computerized crash system and these left 5986 samples are used for the further analysis. Then a careful review of these selected crash data is performed to check and identify the taxi involved crash records that occurred in Xi'an during 2006 2011 and 612 valid reports (10.22\% of total samples) are finally obtained, in which $11.76 \%$ proved fatal, $27.45 \%$ resulted in serious injuries and the rest in slight injuries.

In addition, a limited questionnaire survey for taxi firms and individual drivers are gone through to understand the annual 
registration, licensing statistics of taxi and their experiences or opinions about taxi operation over these six years, in which the sampled drivers belong to different taxi firms. However, most of them are very conservative and show less interest for cooperation. Even the present 22 companies do not respond fully to all the surveyed questions. Thus, the analysis of this data set is limited for this study.

\section{Drivers Characteristics}

\subsection{Gender, Age, Marital Status and Education}

Table 1 shows the statistical characteristics of taxi drivers involved in crashes. Male drivers are more involved in taxi-related crashes ( $92.16 \%$ of crashes) than female drivers. Of course, taxi use has been associated primarily to male drivers in most China cities, and thus the number of crashes occurred is more related with this population group, especially for those older than 40 years. But during recent years, this trend has changed constantly with more females' engagement in the taxi use.

Table 1 Distribution of drivers involved by age group

\begin{tabular}{|c|c|c|}
\hline Driver elements & Count & Percent $/ \%$ \\
\hline \multicolumn{3}{|l|}{ Gender } \\
\hline Male & 564 & 92.16 \\
\hline Female & 48 & 7.84 \\
\hline \multicolumn{3}{|l|}{ Marital status } \\
\hline Married & 536 & 87.58 \\
\hline Unmarried & 76 & 12.42 \\
\hline \multicolumn{3}{|l|}{ Education background } \\
\hline Illiterate & 45 & 7.35 \\
\hline Primary school & 94 & 15.36 \\
\hline Middle school & 283 & 46.24 \\
\hline Junior high school & 179 & 29.25 \\
\hline Higher education & 11 & 1.80 \\
\hline \multicolumn{3}{|l|}{ Age group } \\
\hline$<18$ & 3 & 0.49 \\
\hline $18-20$ & 71 & 11.60 \\
\hline $21-25$ & 11 & 1.80 \\
\hline $26-30$ & 142 & 23.20 \\
\hline $31-35$ & 179 & 29.25 \\
\hline $36-40$ & 117 & 19.12 \\
\hline $41-45$ & 63 & 10.29 \\
\hline $46-50$ & 14 & 2.29 \\
\hline $50-55$ & 8 & 1.31 \\
\hline $55-60$ & 3 & 0.49 \\
\hline$>60$ & 1 & 0.16 \\
\hline
\end{tabular}

Obviously, the risk perception skills of drivers have significant effects on the occurrence of crashes. Males are believed to have superior driving skills in catching the danger ahead, controlling the vehicles and escaping dangerous situations, and thus they are less likely than female counterparts to be involved in a fatal crash, even under over-speeding conditions. Moreover, males perceive less importance of specific hazardous driving behaviors (e.g., not using seat belts, fatigue, mobile use in driving) than female drivers, and carelessness and extraction in driving also induce the male drivers to perceive lower risk than the females while watching the roadway geometrics and environment.

Marital status and education level are identified another two major factors affecting the occurrence of crashes (Sullman, Stephens, Kuzu, 2013; Demirer, Durat, Hasimoglu, 2012). Among the reviewed 612 samples, 63 divorced or widowed taxi drivers accounting for 10.29 percentages of total records have experienced at least one fatal or slight crash in the married sample group, with respect to marital status. Therefore, a nice family life helps maintain peace of mind and decrease the likelihood of crash involvement. The reviewing check of taxi involved crashes also shows illiterate taxi drivers account for more than $7 \%$, while $1.8 \%$ has a higher education in a specific bachelor degree, and most of the involved taxi drivers have a middle or junior high school education.

The mean age of sampled crash involved drivers is 36.7 years with a standard deviation of 6.73 years. As shown in Table 1, the distribution of drivers by age shows that the largest age group is between 31 and 35 years and about $29.25 \%$ of the taxi drivers are involved in crashes. In addition, the age groups of 26 to 30 and 36 to 40 years old have the second and third highest frequency of crashes in Xi'an, respectively, and about $71.57 \%$ of total crash related taxi drivers are aged between 26 to 40 years, due to the largest number of licensed taxis and drivers of these groups. It should also be pointed out that 71 younger taxi drivers accounting for 11.6 percent of samples have been associated with crash involvement, because of their lower driving experience and immaturity in dealing with potential dangers or emergency conditions.

\subsection{License Status and Driving Experience}

Sufficient reports agreed that drivers licensing (GDL) influences the frequency of crashes involved (Lyon, Pan, Li, 2012). Accordingly, there is a clear and strict governmental regulation requiring that the taxi driver must carry a General Driving License (GDL) while driving a taxi vehicle, and it is illegal for him or her to work with a Private Driving License (PDL). However, 57 cases out of the total 612 samples involve illegal drivers with PDL, due to (1) these drivers in PDL have joined in the taxi companies with their private cars; (2) licensed process and annual inspection for taxi is not supervised effectively and present law enforcement is not sufficient to get them off the work. 
Table 2 Distribution of taxi related crashes from 2006 to 2011

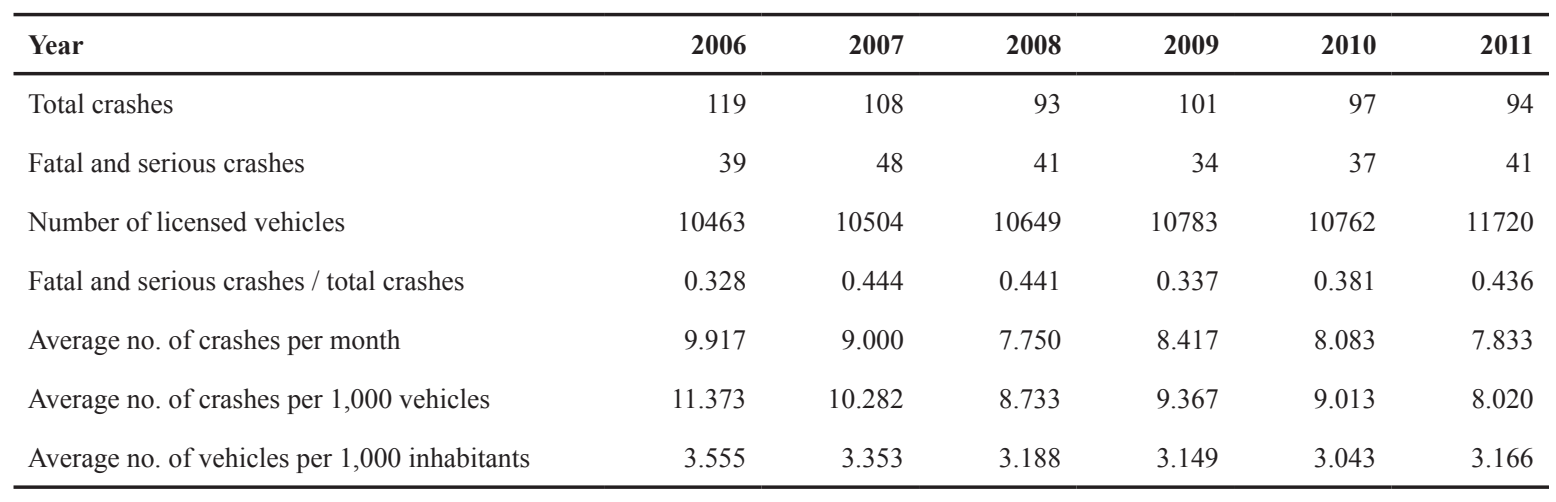

Like the rider's age, the driving experience is also considered to be another significant factor influencing the risk perception and response (Underwood, Ngai, Underwood, 2013). A typical road hazard allows the driver just less than two seconds to perceive the risk, evaluate the danger, make a collision avoidance decision, and complete the overall action. But inexperienced drivers might tend to identify less risk, or fail to detect or react properly to the danger. The similar findings are also found through this research, as shown in Fig. 1. The taxi drivers with 1 3 years driving experience are more likely than other groups to be involved in a motor vehicle crash, accounting for $25.49 \%$ of all records, followed by those for $3 \sim 5$ years and less than 1 year, respectively.

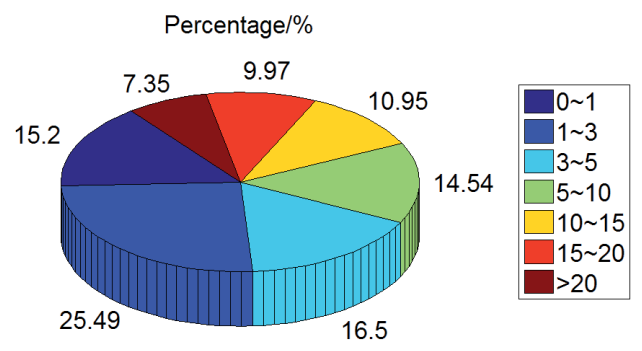

Fig. 1 Distribution of drivers involved by driving experiences

\section{Crash distribution}

\subsection{Temporal Statistics}

An overwhelmingly 119 crashes occurred in the year 2006 with a decreasing trend in the forthcoming five-year period. However, the alarming number of fatal and serious records among the total reported cases remains almost unchangeable during the years 2006 2011. Statistics also demonstrate that the taxi safety situation in Xi'an was still a serious concern and will last for a long period as shown by the proportion of fatal and serious reports among the overall observations, which are presented in Table 2 . Fatal injuries and fatalities crashes including at least one death or severe injury occurred at a daily average of 0.09 to 0.13 , which meant perhaps one life was lost weekly because of taxi crashes.

Fig. 2 presents the distribution of taxi involved crashes and those cases involving serious injuries and fatalities by the day of the week. The trends observed confirmed the concerns of traffic

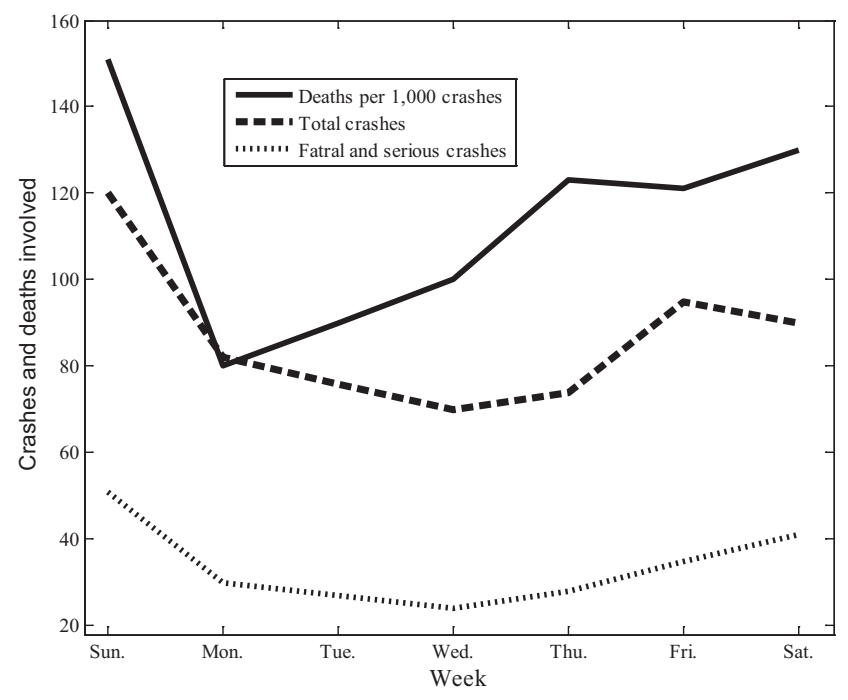

Fig. 2 Taxi crash distribution by day of the week

policies relative to weekends, especially Sundays, similar to a motor vehicle safety issue (Wang et al., 2011). Obviously, the weekends had the highest frequency of taxi involved crashes, accounting for more than one-third of the total records. In terms of fatal and serious cases, the percentage of reviewed crashes was 21.3 and 17.5, respectively, on Sundays and Saturdays. In addition, the deaths per 1,000 crashes decreased from 15.13 in 2006 to 8.24 in 2007 but substantially increased to 13.04 in 2011.

The number of licensed vehicles increased slowly during the years 2009 2011, and following this period saw an expansion of permanent and transient population. Accordingly, Xi'an carried out a traffic safety improvement project for public transit at the ending of year 2007, aiming at improving the total safety level of buses and taxis through newly and updating facilities as well as driver training and specific education. Fortunately, it achieved a significant success in 2008 and almost all variables representing in Table 2 decreased over the last three years. The average number of crashes per month decreased from 9.917 in 2006 to 7.833 in 2011 and experienced a minimum 7.750 in 2008. The average no. of crashes per 1,000 vehicles also fluctuated between 8.0 and 11.3. Fig. 3 presents the monthly distribution of taxi involved crashes, depending on the crash samples in Xi' an from January 2006 to December 2011. According to these six years' records, it indicates that more observations occurred 
on the winter days and about $39.71 \%$ of the total crashes appeared during November, December and January over this period. More seriously, 42.08 percent among the sampled 240 fatal and serious crashes were restrained in the same period.

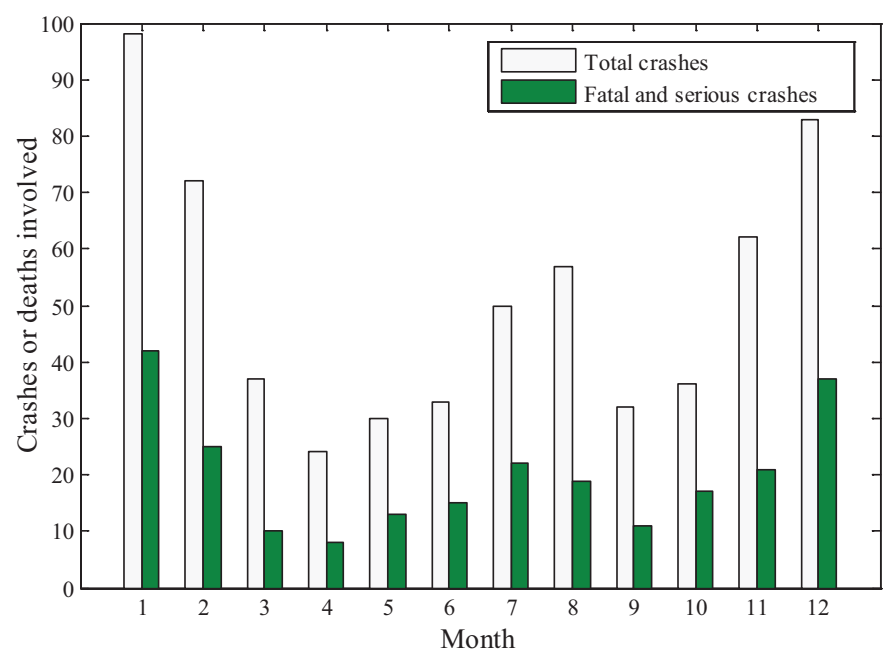

Fig. 3 Taxi crash distribution by month

Through the further data mining of 612 samples, it is found that the majority of taxi related crashes representing about $59.2 \%$ appeared during the day period of 8:00 to $18: 00$ and the percentage of reported crashes was about 21.7 that occurred at the night period from 18:00 to 22:00 (see Fig. 4). In addition, $15.8 \%$ and $13.6 \%$ of total crashes occurred at two peak hours 8:00 10:00 and 16:00 18:00, respectively, for more than ever passengers need taxi services at these two periods, particularly at the morning rush hour. The interval from 22:00 to 24:00 was also a dangerous period for taxi drivers and 5.88 percent of the reviewed 612 crashes appeared due to fatigue, lack of effective night lighting, et al, which is especially true at the Ming City Wall area and on the winter nights. Moreover, the percentage of fatal and serious crashes at night period (22:00 6:00) was extremely higher than that at the day time.

\subsection{Spatial Layout}

As shown in Fig. 5a, most of the taxi crashes, $69.8 \%$ of all, occurred in major roads, representing $43.5 \%$ and $26.3 \%$ for arterials and sub-arterials, respectively. This distribution was expected due to the fact that more than $60 \%$ of daily traffic volume is supported by these two types of urban roads. More seriously, about 18.6 percent of taxi crashes appeared on the three expressways, namely 2 Ring Rd., 3 Ring Rd., and Raocheng Freeway, which was significantly associated with the over speeding. All these show the importance of providing special emphasis not only to private cars but also to taxi vehicles to limit their driving velocity.

Fig. $5 \mathrm{~b}$ also shows that over $15.85 \%$ taxi involved crashes occurred at unsignalized intersections or around areas (inter. B), but the signalized intersections behave an effective performance in preventing the occurrence of crashes, including the taxi involvement cases, and among the reviewed 612 samples, crashes within or around the signalized intersections account for about $6.70 \%$ for the period analyzed. In Xi' an city, traffic flows with the roundabouts are too much complex and not easy to be organized due to the conflicts. Accordingly, some are controlled by signals, in order to reduce the conflicts between traffic vehicles and improve the safety performance. But the statistics also shows that 45 crashes occurred at the roundabouts, mainly referring to the slight injuries from side scrapes and minor rearend/merge collisions. So far, it's easily concluded that segments are the most dangerous locations for taxi drivers, accounting for nearly $70 \%$ of all crashes, and it should be paid specific treatments, followed by the intersections without signal control, as claimed in previous findings (Geurts et al., 2006)

In terms of crashes on segments, $23.3 \%$ were observed as fatality and serious injury crashes, as a whole due primarily to exceeding the speed limit. In addition, Xi' an study showed that about $2.94 \%$ of taxi crashes had contributed to the interchange locations, but the tunnels had witnessed few crashes over the same period.

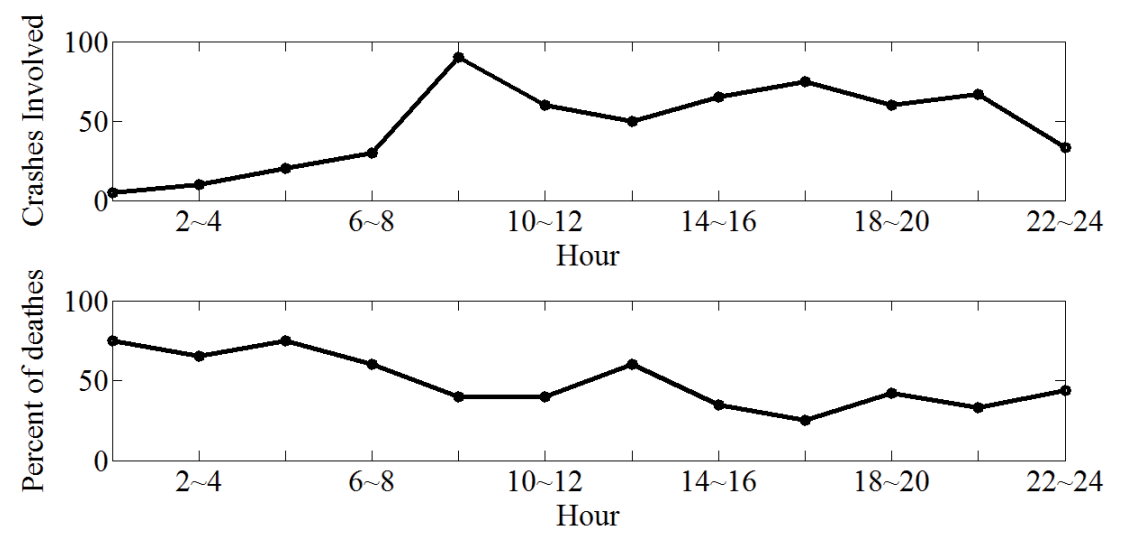

Fig. 4 Taxi crash distribution by hour 

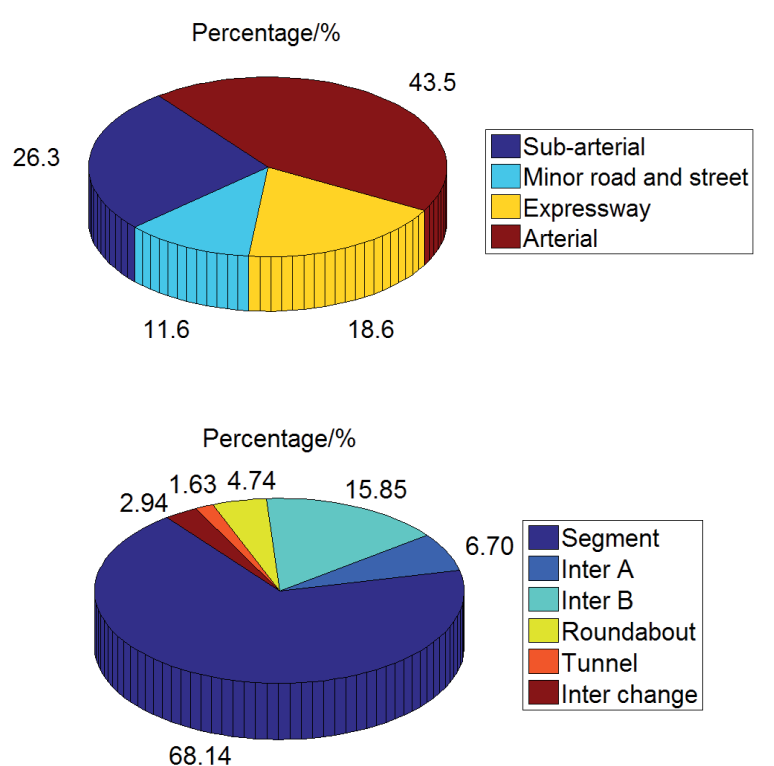

Fig. 5 Spatial distribution of taxi crashes

\subsection{Crash Type}

As shown in Fig. 6a, more than half of taxi vehicles were involved in passenger car collisions, followed by pedestrian, fixed-object and motorcycle crashes, accounting for $12.42 \%$, $10.46 \%$ and $8.33 \%$ of all samples, respectively, and pedestrian involved crashes ranked five. Obviously, the taxi crashes involving pedestrians, bicycles and motorcycles accounted for 160 cases or approximately $26.1 \%$ of the total crashes reviewed.

With respect to crash type, presented in Fig. 6b, the largest number of taxi crashes was sideswipe type (44.77\%), followed by rear-end $(29.90 \%)$ and head on $(15.85 \%)$, respectively. Since most of the taxi drivers fight against time for money and thus driving over the speed limit is a common problem in the taxi market of China cities (Wang et al., 2011). Therefore, it is not surprising that the proportion of taxi-related crashes due to "following too closely" was higher than that for other causes.

The type or pattern of roadway segments and intersections has closely associated with the occurrence of crashes, including taxi involved cases, because the geometric designs of segments and intersections affect the vision scope, speed choice and risk perception of drivers and distribution of traffic volume (Mario and Gianluca, 2012). In this study, we explored the distributions of taxi crashes according to the types of segments by the number of dividers and intersections, as shown in Table 3, in which sideswipes A and B refer to the sideswipe collisions of the same direction and opposite direction, respectively. Of course, intersection's influence area is limited within $50 \mathrm{~km}$ along the entrance lanes.

Of course, 417 cases or $68.14 \%$ of the total records occurred on the segments, and a relatively large proportion of crashes occur on undivided six-lane segments $(17.81 \%$ of all samples) and four-legged intersection (15.36\%), followed by those on four-lane segments without median (82 cases out of 612 records) and eight-lane segments ( 77 cases or $12.59 \%$ in total).
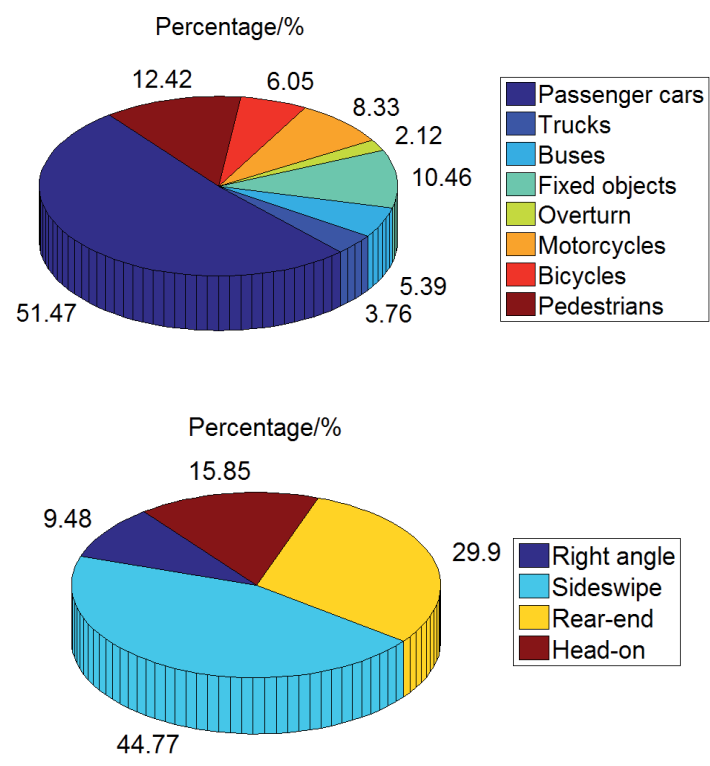

Fig. 6 Distribution of crashes by collision type

\section{Crash Causes}

\subsection{Overall Description}

Obviously, the occurrence of crashes is a complex procedure that unavoidably involves numerous of contributory factors. If a driver obeys traffic laws, he will not be easily involved in a crash, as many road safety experts and engineers have claimed before (Chin and Huang, 2009; Sullman, Stephens, Kuzum, 2014). But he/she does not, a danger crash is just going on the road! Thus, nearly all the crashes attribute most of the blame to the driver errors or risk driving behaviors, beyond roadway alignment, roadside facilities, traffic volume, environment, etc.

Fig. 7 shows the distribution of taxi crash by cause associated with the 612 samples reviewed. It can be observed that 544 taxi crashes accounting for nearly $90 \%$ of all records are caused by the driver behavior. The other major contributory cause is weather and environment (3.43\%) followed by roadway geometric (3.27\%), and other factors (2.29\%). These findings related to taxi crashes are similar to those of motor vehicle injuries and facilities in Xi' an city for the period analyzed, where $86 \%$ of all accidents were associated with improper driving behaviors (Wang, 2011).

Percentage $/ \%$

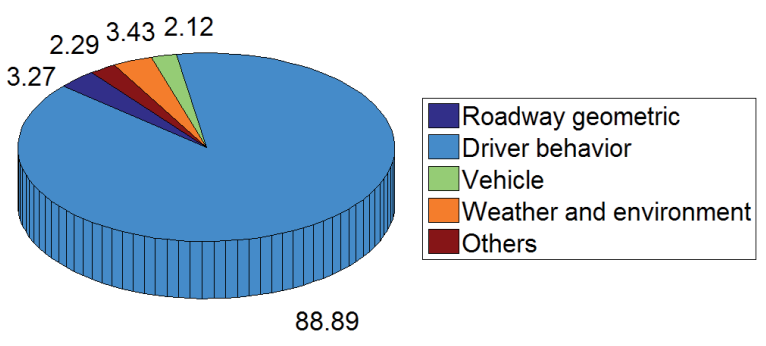

Fig. 7 Perceived contributory factors of motorcycle crashes 
Table 3 Composition of crashes on Each Kind of Links and Intersections

\begin{tabular}{|c|c|c|c|c|c|c|c|}
\hline Crash type & Head on & Right angle & Rear end & Sideswipe A & Sideswipe B & Overturn & Total \\
\hline One-lane segments & 0 & 2 & 1 & 1 & 1 & 0 & 5 \\
\hline Two-lane segments without median & 1 & 6 & 13 & 4 & 6 & 3 & 33 \\
\hline Four-lane segments without median & 9 & 11 & 26 & 16 & 11 & 9 & 82 \\
\hline Four-lane segments with median & 3 & 17 & 8 & 13 & 9 & 1 & 51 \\
\hline Six-lane segments without median & 13 & 25 & 31 & 17 & 9 & 14 & 109 \\
\hline Six-lane segments with median & 6 & 9 & 19 & 8 & 13 & 5 & 60 \\
\hline Eight-lane segments & 3 & 12 & 35 & 13 & 9 & 5 & 77 \\
\hline Three legged intersections $(\mathrm{T} / \mathrm{Y})$ & 3 & 16 & 11 & 15 & 0 & 1 & 46 \\
\hline Four legged intersections $(+/ \times)$ & 8 & 23 & 9 & 37 & 14 & 3 & 94 \\
\hline Five legged intersections & 0 & 2 & 1 & 4 & 1 & 0 & 8 \\
\hline Roundabouts & 0 & 15 & 2 & 11 & 1 & 0 & 29 \\
\hline Interchanges & 2 & 7 & 1 & 6 & 2 & 0 & 18 \\
\hline Total & 48 & 145 & 157 & 145 & 76 & 41 & 612 \\
\hline
\end{tabular}

\subsection{Driver behavior}

Table 4 presents the causes of along with the frequencies of improper driver behaviors in the sampled 612 taxi crashes, which clearly indicates that the percentages of improper driver behaviors are very high for all causes. From the statistics, nine improper or illegal behaviors of drivers with the highest frequency were identified and appeared 1071 times in the study sample. That is, the proportion of these most frequent behaviors is 1.75 times (1071/612) per crash, and it is even much worse for the fatal and serious crashes, for the same measure grows to 3.01. Thus, the probability of involvement in a fatal crash, for a taxi driver with improper or illegal driving habits, is significant higher that those with good behaviors (Kaplan and Prato, 2012).
In addition, driving too fast or over speed limits is the most dangerous and illegal behavior and it appeared in nearly 50\% of the study samples and over $77 \%$ of the fatal and serious ones, respectively. The appearance frequency of safety belt not used and disregarding signs or signals are both too high to be neglected in driving education and daily traffic management.

\subsection{Weather Effects}

Previous studies stated that the adverse weather has an effect on the crash frequency and injury severity, due to the degradation of pavement friction and visibility (Jung, Qin, Noyce, 2011). Fig. 8 shows the effects of weather and brightness on taxi involved by percentage, which indicates that occurrence of

Table 4 Frequency of improper driver behaviors in taxi crashes

\begin{tabular}{lrrrrrr}
\hline & \multicolumn{3}{c}{ Total crashes } & & Fatal and serious crashes \\
\cline { 2 - 6 } Cause & $\mathrm{N}$ & $\%$ & Frequency & $\mathrm{N}$ & \% & Frequency \\
\hline Driving over speed limits & 304 & 49.67 & 0.497 & 185 & 77.08 & 0.771 \\
Disregarding signs or signals & 117 & 19.12 & 0.191 & 77 & 32.08 & 0.321 \\
Following too closely & 84 & 13.73 & 0.137 & 53 & 22.08 & 0.221 \\
Driving wrong way & 37 & 6.05 & 0.060 & 16 & 6.67 & 0.067 \\
Failing to give yield & 81 & 13.24 & 0.132 & 29 & 12.08 & 0.121 \\
Changing lane frequently & 65 & 10.62 & 0.106 & 14 & 5.83 \\
Using a cell phone & 81 & 13.24 & 0.132 & 105 & 43.75 & 0.058 \\
Fatigued or illness & 39 & 6.37 & 0.064 & 32 & 13.33 \\
Safety belt not used & 263 & 42.97 & 0.430 & 212 & 88.33 \\
Others & 79 & 12.91 & 0.129 & 18 & 0.133 \\
\hline Total & 1150 & -1.879 & 741 & 0.883 \\
\hline
\end{tabular}



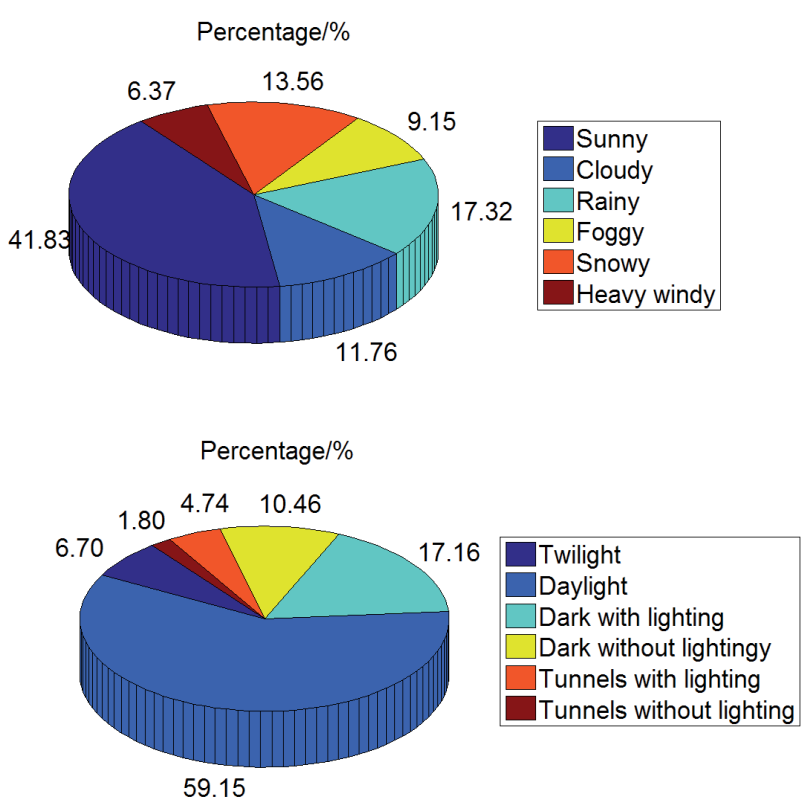

Fig. 8 Percentage of taxi involved crashes under different weather and brightness conditions

crashes is closely associated with the adverse weather conditions. Obviously, over $17 \%$ of the reviewed crashes occurred on the rainy days, followed successively by on the snowy $(13.56 \%)$, the cloudy $(11.76 \%)$ and foggy days $(9.15 \%)$. In addition, the frequency of crashes is also potentially related to brightness and it can be seen from Fig. 8 that the twilight is a dangerous period for most taxi drivers due to the fatigue and effects of sun glare, and the urban tunnel is also a typical location with higher risk of being involved in a crash accounting for $6.54 \%$ of all cases. More seriously, roads without effective lightings witnessed 64 crashes, particularly for minor roads and streets, which require lighting improvement efforts.

\subsection{Working Fatigue}

For a driver, driving a taxi is a high-intensity work rather than a flexible one. Long driving hours and long distance traveled daily may put more physical and mental pressure on the drivers that will bring the high risk of fatigue, being improper/ illegal behaviors and even being involved in a crash. Accordingly, the average working state of taxi drivers surveyed in this study include: number of daily trips, daily traveled distance, and daily working hours.

According to the driver questionnaire, the result revealed that each taxi driver, on average, travels 386.4 (st. dev is 105.7) kilometers, works 9.72 (st. dev. is 0.93) hours, and completes 33.64 (st. dev. is 5.58) trips served daily in the past eight months of 2012 , which excesses $21.5 \%$ of the officially 8 working hours maximum per day.

The average traveled distance and average occupancy per trip are 16.35 kilometers and 1.53 passengers, respectively, and the taxi drivers work 6.2 days per week. For a taxi driver in Xi'an, therefore, the average number of trips per year is 12,278 trips serving 18,786 passengers. Reconsidering the number of taxi vehicle in 2011 is 11,720 , thus, the total number served by all taxis equal to be 603,219 passengers every day. It is estimated that the current total daily number served by the mass rail, public buses, and taxis in Xi'an is 2,621,310 passengers, and the taxis serve about $23.01 \%$ of the total passengers for daily trips.

\section{Conclusion}

In this study, taxi involved crashes over 2006 2011 in Xi' an has been evaluated using the selected 612 samples among the original 6259 crash reports so as to understand the characteristics of crash occurrence and distribution very well and recommend operational and safety improvement measures of this transport service.

It appears from this study that Driver's personal characteristics, such as gender, age, marital status, education, license status and driving experience, etc., have a potential effect on the frequency of taxi crashes. The male drivers with lower education background are much more likely to be involved in a crash. The high percentage of taxi drivers aged 26 40 years, accounting for $71.57 \%$ of all drivers involved in crashes, requires further deep investigations in order to provide possible treatments or special training programs aiming at enhancing their capability and safety performance of being in this business, which could help researchers and managers understand why and how the crashes occur as well as how to reduce or prevent them over a long period of time.

Additionally, the amount of driving experience is a significant contributory factor to crashes and experienced taxi drivers are capable of perceiving the risk ahead, evaluating the danger and making a collision avoidance decision more effectively and properly. The review of taxi crash samples indicates that the group with $3 \sim 5$ years experience continues to be more frequently involved in a crash, which requires specific attention.

The trend and pattern of taxi involved crashes vary significantly, depending on the particular time of day, the day of the week, and month of the year. This study shows that $39.71 \%$ of the total crashes occurred during November, December, and January, and a large proportion of the crashes in this study recorded at weekends. In addition, nearly $60 \%$ of all cases appeared during the day period of 8:00 to 18:00 and the periods of 8:00 10:00 and 16:00 18:00 became the two most dangerous time accounting for $29.4 \%$ of the total records. Subsequently, it should be pointed out that the proportion of fatal and serious crashes at night period was extremely higher than that at the day time.

The statistics indicates that 544 cases or approximate $89 \%$ of all crash records are associated with driver's behavior factors, in which driving over speed limits, safety belt not used, and disregarding signs or signals rank the first three types of the most frequently improper or illegal behaviors. The corresponding specific campaign including real-time monitoring and educational programs is urgently needed so as to make 
the drivers aware of their threat towards other road users and potential danger of being involvement in a crash due to improper or illegal behaviors.

Law and enforcement always play an important role, in part, in increasing safety performance. Taxi drivers' work is heaviest at rush hours, in bad weather, and on holidays. However, the gap between the actual daily working hours and the existing regulations concerning the taxi service should be narrowed through strict rules and serious enforcement. That is, the existing regulations limit a number of working hours in a day to be no more than 8 hours; however, this study found that the taxi drivers work 9.72 hours averagely per day, exceeding $21.5 \%$ of the officially maximum restriction. Most of taxi drivers are required, on a daily basis, to pay a fixed amount of money to the firm. Accordingly, the drivers have to be pushed unconsciously to work average 9.72 hours every day and 6.2 days per week, and much longer at rush hours, in bad weather, and on holidays. This situation results in the high risk of being involved in crashes among the group of taxi drivers due to fatigue and stress on the road for a long duration of time.

There are some important notes from this study useful for the understanding and treating with the taxi involved crashes. It is very important, but very difficult, to judge and determine precisely why, when, and how such crash will occur, since the occurrence of crashes is a combined result of several contributory factors. The findings suggest that there is an important role in recommending driver's specific training and education programs and exploring ITS based management tools and policy initiatives for taxi industry (Miwa et al., 2013). There is a need for continued or more in-depth discussion in certain topics. The authors believe that it will become an important topic that has not ever been drawn enough attention in past and further research will focus on the systematic combination of countermeasures focusing on the licensing qualification regulations, skills training course, limitation rule of working hours and annual inspection policy, etc.

\section{Acknowledgement}

The project presented in this article is supported by the Key Programs of Department of Transport of Shaanxi, China (No. 14-29R). The authors gratefully acknowledge Xi'an Traffic Policy for data collection efforts.

\section{References}

Chin, H. C., Huang, H. L. (2009) Safety assessment of taxi drivers in Singapore. Transportation Research Record. 2114. pp. 47-56. DOI: $10.3141 / 2114-06$

Christoforou, Z., Milioti, C., Perperidou, D., Karlaftis, M. G. (2012) Investigation of taxi travel time characteristics. Advances in Transportation Studies. 27. pp. 17-30. DOI: $10.4399 / 97888548486722$

Demirer, A., Durat, M., Hasimoglu, C. (2012) Investigation of seat belt use among the drivers of different education levels. Safety Science. 50 (4). pp. 1005-1008. DOI: 10.1016/j.ssci.2011.12.013
Firestone, R. T., Mihaere, K., Gander, P. H. (2009) Obstructive sleep apnoea among professional taxi drivers: a pilot study. Accident Analysis \& Prevention. 41 (3). pp. 552-556. DOI: 10.1016/j.aap.2009.02.006

Fleiter, J. J., Gao, L. P., Qiu, C., Shi, K. (2009) Availability, functionality, and use of seat belts in Beijing taxis prior to the 2008 Beijing Olympic Games. Accident Analysis \& Prevention. 41 (2). pp. 342-344. DOI: 10.1016/j.aap.2008.12.007

Geurts, K., Wets, G., Brijs, T., Vanhoof, K., Karlis, D. (2006) Ranking and selecting dangerous crash locations: Correcting for the number of passengers and Bayesian ranking plots. Journal of Safety Research. 37 (1). pp. 83-91. DOI: 10.1016/j.jsr.2005.10.020

Hitosugi, M., Gomei, S., Okubo, T., Tokudome, S. (2012) Sudden illness while driving a vehicle - a retrospective analysis of commercial drivers in Japan. Scandinavian Journal of Work, Environment \& Health. 38 (1). pp. 84-87. DOI: $10.5271 /$ sjweh.3189

Jung, S., Qin, X., Noyce, D. A. (2011) Injury severity of multivehicle crash in rainy weather. Journal of Transportation Engineering. 138 (1). pp. 50-59. DOI: 10.1061/(ASCE)TE.1943-5436.0000300

Kaplan, S., Prato, C. G. (2012) The application of the random regret minimization model to drivers' choice of crash avoidance maneuvers. Transportation Research Part F: Traffic Psychology and Behaviour. 15 (6). pp. 699-709. DOI: 10.1016/j.trf.2012.06.005

La, Q. N., Lee, A. H., Meuleners, L. B., Duongc, D. V. (2013) Prevalence and factors associated with road traffic crash among taxi drivers in Hanoi, Vietnam. Accident Analysis \& Prevention. 50. pp. 451-455. DOI: 10.1016/j.aap.2012.05.022

Lam, L. T. (2004) Environmental factors associated with crash-related mortality and injury among taxi drivers in New South Wales, Australia. Accident Analysis \& Prevention. 36 (5). pp. 905-908.

DOI: 10.1016/j.aap.2003.10.001

Lyon, J. D., Pan, R., Li, J. (2012) National evaluation of the effect of graduated driver licensing laws on teenager fatality and injury crashes. Journal of Safety Research. 43 (1). pp. 29-37. DOI: 10.1016/j.jsr.2011.10.007

Maag, U., Vanasse, C., Dionne, G., Laberge, N. C. (1997) Taxi drivers' accidents: how binocular vision problems are related to their rate and severity in terms of the number of victims. Accident Analysis \& Prevention. 29 (2). pp. 217-224. DOI: 10.1016/S0001-4575(96)00075-9

Mann, R. E., Stoduto, G., Ialomiteanu, A., Asbridge, M., Smart, R. G., Wickens, C. M. (2010) Self-reported collision risk associated with cannabis use and driving after cannabis use among Ontario adults. Traffic Injury Prevention. 11 (2). pp. 115-122. DOI: 10.1080/15389580903536704

Mario, D. L., Gianluca, D. A. (2012) Freeway safety management: case studies in Italy. Transport. 27 (3). pp. 320-326. DOI:10.3846/16484142.2012.724447

Mitsakis, E., Stamos, I., Grau, M. J., Morfoulaki, M. (2015) Bus Drivers Risk Perception of Roadway Hazards. Periodica Polytechnica Transportation Engineering. 43 (1). pp. 15-21. DOI: 10.3311/PPtr.7481

Miwa, T., Ishiguro, Y., Yamamoto, T., Morikawa, T. (2013) Allocation planning for probe taxi devices based on information reliability. Transportation Research Part C: Emerging Technologies. 34. pp. 55-69. DOI: $10.1016 /$ j.trc.2013.05.004

Newnam, S., Mamo, W. G., Tulu, G. S. (2014) Exploring differences in driving behaviour across age and years of education of taxi drivers in Addis Ababa, Ethiopia. Safety Science. 68. pp. 1-5. DOI: 10.1016/j.ssci.2014.02.012

Rao, A. M., Rao, K. R. (2015) Free Speed Modeling for Urban Arterials - A Case Study on Delhi. Periodica Polytechnica Transportation Engineering. 43 (3). pp. 111-119. DOI: 10.3311/PPtr.7599 
Sokolovskij, E., Prentkovskis, O. (2013) Investigating traffic accidents: the interaction between a motor vehicle and a pedestrian. Transport. 28 (3). pp. 302-312. DOI: $10.3846 / 16484142.2013 .83177$

Sullman, M. J. M., Stephens, A. N., Kuzu, D. (2013) The expression of anger amongst Turkish taxi drivers. Accident Analysis \& Prevention. 56. pp. 42-50. DOI: 10.1016/j.aap.2013.03.013

Tseng, C. M. (2013) Operating styles, working time and daily driving distance in relation to a taxi driver's speeding offenses in Taiwan. Accident Analysis \& Prevention. 52. pp. 1-8. DOI: 10.1016/j.aap.2012.11.020

Underwood, G., Ngai, A., Underwood, J. (2013) Driving experience and situation awareness in hazard detection. Safety Science. 56. pp. 29-35.

DOI: $10.1016 /$ j.ssci.2012.05.025
Wang, Y. G., Huang, S. S., Xiang, W. S., Pei, Y. L. (2011) Multipattern road traffic crashes and injuries: a case study of Xi'an city. Acta Polytechnica Hungarica. 8 (4). pp. 171-181

Wang, Y. G., Li, L. C., Feng, L., Peng, H. (2014) Professional drivers' views on risky driving behaviors and accident liability: a questionnaire survey in Xining, China. Transportation Letters: The International Journal of Transportation Research. 6 (3). pp. 126-135.

DOI: $10.1179 / 1942787514 Y .0000000019$ 